\title{
A Critique of the International Consensus Statement on ADHD
}

\author{
Sami Timimi ${ }^{1,3}$ and 33 Coendorsers $^{2}$
}

KEY WORDS: ADHD; international consensus; critique.

Why did a group of eminent psychiatrists and psychologists produce a consensus statement that seeks to forestall debate on the merits of the widespread diagnosis and drug treatment of attention deficit hyperactivity disorder (ADHD) (Barkley et al., 2002)? If the evidence is already that good then no statement is needed. However, the reality is that claims about ADHD being a genuine medical disorder and psychotropics being genuine correctives have been shaken by criticism.

Not only is it completely counter to the spirit and practice of science to cease questioning the validity of ADHD as proposed by the consensus statement, there is an ethical and moral responsibility to

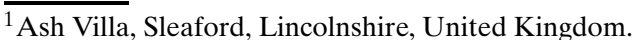

${ }^{2}$ Joanna Moncrieff (University College London, London, United Kingdom); Jon Jureidini (Department of Psychiatry, University of Adelaide, Adelaide, Australia); Jonathan Leo (Western University of Health Sciences, Pomona, California); David Cohen (College of Health and Urban Affairs, Florida International University, Miami, Florida); Charles Whitfield (PO Box 420487, Atlanta Georgia); Duncan Double (Norfolk Mental Health Care NHS Trust, Norwich, United Kingdom); Jonathan Bindman (Institute of Psychiatry, London, United Kingdom); Henry Andrews (Barnet Enfield and Haringay NHS Trust, Chase Farm Hospital, Enfield, United Kingdom); Eia Asen (Marlborough Family Service, Marlborough Place, London, United Kingdom); Pat Bracken (Centre for Citizenship and Community Mental Health, School of Health Studies, University of Bradford, Bradford, United Kingdom); Barry Duncan (8100 Royal Palm Blvd, Suite 108, Coral Springs, Florida); Michaele Dunlap (818 NW 17th Avenue, Portland, Oregon); Albert Galves (Salud Family Health Centers, Fort Lupton, Colorado); Michael Green (4 Martindale Road, London, United Kingdom); Tom Greening (1314 Westwood Blvd, Suite 205, Los Angeles, California); Janice Hill (the Overload Network Scotland and England, 58 North Fort Street, Edinburgh, United Kingdom); Rhodri Huws (St. Georges Community Health Centre, Sheffield, United Kingdom); Bertram
}

do so. History teaches us again and again that one generation's most cherished therapeutic ideas and practices, especially when applied on the powerless, are repudiated by the next, but not without leaving countless victims in their wake. Lack of acknowledgement of the subjective nature of our psychiatric practice leaves it wide open to abuse (Kopelman, 1990). For these reasons we, another group of academics and practitioners, feel compelled to respond to this statement.
Karon (Michigan State University, East Lansing, Michigan); Brian Kean (Southern Cross University, Australia); Michael McCubbin (Faculty of Nursing Sciences, Laval University, Chemin Sainte-Foy, Quebec, Canada); Begum Miatra (Lower Clapton Child and Family Consultation Service, London, United Kingdom); Loren Mosher (Soteria Associates, 2616 Angell Avenue, San Diego, California); Sue Parry (ADD Watch Hawaii, Honolulu, Hawaii); S DuBose Ravenel (611 Lindsay Street, Suite 102, High Point, North Carolina); Dominick Riccio (International Centre for the Study of Psychiatry and Psychology, 1036 Park Avenue, New York, New York); Richard Shulman (Volunteers in Psychotherapy Inc. 7 South Main Street, West Hartford, Connecticut); Jeanne Stolzer (University of Nebraska, Otto Olsen 205D, Kearney, Nebraska); Phil Thomas (Centre for Citizenship and Community Mental Health, School of Health Studies, University of Bradford, Bradford); Graham Vimpani (Hunter Children's Heal Network, Wallsend, Australia); Al Wadsworth (Marinoto North Youth Services, Auckland, New Zewland); Dave Walker (Yakama Indian Health Service, Toppenish WA, Yakama Nation Washington); Norbert Wetzel (Princeton Family Institute, Princeton); Rupert White (Banham House, Bodmin Hospital, Bodmin, Cornwall, United Kingdom). ${ }^{3}$ Address all correspondence to Sami Timimi, Consultant Child and Adolescent Psychiatrist, Ash Villa, Sleaford, Lincolnshire NG34 8QA, United Kingdom; e-mail: stimimi@talk21.com. 


\section{MERITS OF THE ADHD DIAGNOSIS}

The evidence does not support the conclusion that ADHD identifies a group of children who suffer from a common and specific neurobiological disorder. There are no cognitive, metabolic, or neurological markers for ADHD and so there is no such thing as a medical test for this diagnosis. There is obvious uncertainty about how to define this disorder, with definitions changing over the past 30 years depending on what the current favourite theory about underlying aetiology is, and with each revision producing a higher number of potential children deemed to have the disorder (Timimi, 2002). It is hardly surprising that epidemiological studies produce hugely differing prevalence rates from $0.5 \%$ to $26 \%$ (Green, Wong, Atkins, Taylor, \& Feinleib, 1999; Taylor \& Hemsley, 1995) of all children.

Despite attempts at standardising criteria, crosscultural studies on the rating of symptoms of ADHD show major and significant differences between raters from different countries (Mann et al., 1992), rating of children from different cultures (Sonuga-Barke, Minocha, Taylor, \& Sandberg, 1993), and even within cultures (for example, rates of diagnosis of ADHD have been shown to vary by a factor of 10 from county to county within the same state in the United States (Rappley, Gardiner, Jetton, \& Howang, 1995)).

There are high rates of comorbidity between ADHD and conduct, anxiety, depression, and other disorders, with about three quarters of children diagnosed with ADHD also fulfilling criteria for another psychiatric disorder (Biederman, Newcorn, \& Sprich, 1991). Such high rates of comorbidity suggest that the concept of ADHD is inadequate to explain clinical reality (Van Praag, 1996).

Neuroimaging research is often cited as "proof" of a biological deficit in those with ADHD, however, after almost 25 years and over 30 studies, researchers have yet to do a simple comparison of unmedicated children diagnosed with ADHD with an age matched control group (Leo \& Cohen, 2003). The studies have shown nonspecific and inconsistent changes in some children in some studies. However, sample sizes have been small and in none of the studies were the brains considered clinically abnormal (Hynd \& Hooper, 1995); nor has any specific abnormality been convincingly demonstrated (Baumeister \& Hawkins, 2001). Most worryingly, animal studies suggest that any differences observed in these studies could well be due to the effects of medication that most children in these studies had taken (Breggin,
1999, 2001; Moll, Hause, Ruther, Rothenberger, \& Huether, 2001; Sproson, Chantrey, Hollis, Marsden, \& Fonel, 2001). Even a U.S. federal government report on ADHD concluded that there was no compelling evidence to support the claim that ADHD was a biochemical brain disorder (National Institutes of Health, 1998). Research on possible environmental causes of ADHD type behaviors has largely been ignored, despite mounting evidence that psychosocial factors such as exposure to trauma and abuse can cause them (Ford et al., 1999, 2000).

With regards the claim that ADHD is a genetic condition that is strongly heritable, the evidence is open to interpretation (Joseph, 2000). ADHD shares common genetics with conduct disorder and other externalising behaviors, and so if there is a heritable component it is not specific to ADHD (Timimi, 2002).

\section{EFFICACY OF DRUG TREATMENT}

The relentless growth in the practice of diagnosis of childhood and adolescent psychiatric disorders has also led to a relentless increase in the amount of psychotropic medication being prescribed to children and adolescents. The amount of psychotropic medication prescribed to children in the United States increased nearly threefold between 1987 and 1996, with over $6 \%$ of boys between the ages of 6 and 14 taking psychostimulants in 1996 (Olfson, Marcus, Weismann, \& Jensen, 2002), a figure that is likely to be much higher now. There has also been a large increase in prescriptions of psychostimulants to preschoolers (aged 24 years; Zito et al., 2000). One study in Virginia found that in two school districts, $17 \%$ of White boys at primary school were taking psychostimulants (LeFever, Dawson, \& Morrow, 1999). Yet in the international consensus statement (Barkley et al., 2002) the authors still believe that less than half of those with ADHD are receiving treatment. Many of the authors of the consensus statement are well-known advocates of drug treatment for children with $\mathrm{AHDH}$ and it is notable that in the statement they do not declare their financial interests and/or their links with pharmaceutical companies.

Despite claims for the miraculous effects of stimulants they are not a specific treatment for ADHD, because they are well known to have similar effects on otherwise normal children and other children regardless of diagnosis (Breggin, 2002; Rapoport et al., 1978). A recent meta-analysis of randomised controlled trials of methylphenidate found that the 
trials were of poor quality, there was strong evidence of publication bias, short-term effects were inconsistent across different rating scales, side effects were frequent and problematic and long-term effects beyond 4 weeks of treatment were not demonstrated (Schachter, Pham, King, Langford, \& Moher, 2001).

The authors of the consensus statement (Barkely et al., 2002) claim that untreated ADHD leads to significant impairment and harm for the afflicted individual; not only do the authors conflate a statistical association with cause but other evidence suggests that drug treatment has at best an inconsequential effect on long-term outcome (Joughin \& Zwi, 1999; Zwi, Ramchandani, \& Joughlin, 2000).

The potential long-term adverse effects of giving psychotropic drugs to children need to cause us more concern than the authors of the consensus statement will allow. Stimulants are potentially addictive drugs with cardiovascular, nervous, digestive, endocrine, and psychiatric side effects (Breggin, 2001, 2002). At a psychological level the use of drug treatment scripts a potentially life-long story of disability and deficit that physically healthy children may end up believing. Children may view drug treatment as a punishment for naughty behaviour and may be absorbing the message that they are not able to control or learn to control their own behavior. Drug treatment may also distance all concerned from finding more effective, long-lasting strategies (Cohen et al., 2002). The child and their carers may be unnecessarily cultured into the attitude of a "pill for life's problems."

\section{A CULTURAL PERSPECTIVE ON ADHD}

Why has ADHD become so popular now resulting in spiralling rates of diagnosis of ADHD and prescription of psychostimulants in the Western world? This question requires us to examine the cultural nature of how we construct what we deem to be normal and abnormal childhoods and child rearing methods. Although the immaturity of children is a biological fact, the ways in which this immaturity is understood and made meaningful is a fact of culture (Prout \& James, 1997). Differences between cultures and within cultures over time mean that what are considered as desirable practices in one culture are often seen as abusive in another.

In contemporary, Western society children are viewed as individuals who have rights and need to express their opinions as well as being potentially vulnerable and needing protection by the state when parents are deemed not to be adequate. At the same time there has been a growing debate and belief that childhood in modern, Western society has suffered a strange death (Hendrick, 1997). Many contemporary observers are concerned about the increase in violence, drug and alcohol abuse, depression, and suicide amongst a generation perceived to have been given the best of everything. Some commentators believe we are witnessing the end of the innocence of childhood, for example, through the greater sexualization and commercialization of childhood interests. It is claimed that childhood is disappearing, through media, such as television, as children have near complete access to the world of adult information leading to a collapse of the moral authority of adults (Postman, 1983). Coupled with this fear that the boundary between childhood and adulthood is disappearing is a growing sense that children themselves are a risk with some children coming to be viewed as too dangerous for society and needing to be controlled, reshaped and changed (Stephens, 1995).

Thus, in the last few decades of the twentieth century in Western culture, the task of child rearing has become loaded with anxiety. On the one hand, parents and teachers feeling the pressure from the breakdown of adult authority discourse, feel they must act to control unruly children; on the other hand they feel inhibited from doing so for fear of the consequences now that people are aware that families can be ruined and careers destroyed should the state decide to intervene. This cultural anxiety has provided the ideal social context for growth of popularity of the concept of ADHD (Timimi, 2002). The concept of ADHD has helped shift focus away from these social dilemmas and onto the individual child. It has been in the best interests of the pharmaceutical industry to facilitate this change in focus. Drug company strategy for expanding markets for drug treatment of children is not confined to direct drug promotion but includes illness promotion (e.g. funding for parent support groups such as CHADD) and influencing research activities (Breggin, 2001; Jureidini \& Mansfield, 2001). Thus the current "epidemic" of ADHD in the West can be understood as a symptom of a profound change in our cultural expectations of children coupled with an unwitting alliance between drug companies and some doctors, that serves to culturally legitimize the practice of dispensing performance enhancing substances in a crude attempt to quell our current anxieties about children's (particularly boys) development (Carey, 2002; DeGrandpre, 1999; Diller, 1998). 
In their consensus statement (Barkley et al., 2002), the authors are at pains to point out that it is not the child's, the parent's or the teacher's fault. However, trying to understand the origins and meaning of behaviors labelled, as ADHD does not need to imply blame. What it does require is an attempt to positively engage with the interpersonal realities of human life. This can be done through individualized family counseling and educational approaches (Breggin, 2000), as well as using multiple perspectives to empower children, parents, teachers, and others (Timimi, 2002).

\section{CONCLUSION}

The authors of the consensus statement (Barkley et al., 2002) sell themselves short in stating that questioning the current practice concerning diagnosis and treatment of ADHD is like declaring the earth is flat. It is regrettable that they wish to close down debate prematurely and in a way not becoming of academics. The evidence shows that the debate is far from over.

\section{REFERENCES}

Barkley, R. et al. (2002). International Consensus Statement on ADHD. Clinical Child and Family Psychology Review, 5, 89111.

Baumeister, A. A., \& Hawkins, M. F. (2001). Incoherence of neuroimaging studies in attention deficit/hyperactivity disorder. Clinical Neuropharmacology, 24, 2-10.

Biederman, J., Newcorn, J., \& Sprich, S. (1991). Comorbidity of attention deficit disorder with conduct, depressive, anxiety and other disorders. American Journal of Psychiatry, 148, 564577.

Breggin, P. (1999). Psychostimulants in the treatment of children diagnosed with ADHD: Part II-Adverse effects on brain and behavior. Ethical Human Sciences and Services, 1, 213-241.

Breggin, P. (2000). Reclaiming our children: A healing solution for crises. Cambridge, MA: Perseus.

Breggin, P. (2001). Talking back to Ritalin: What doctors aren't telling you about stimulants for children (Rev. ed.). Cambridge, MA: Perseus.

Breggin, P. (2002). The Ritalin fact book. Cambridge, MA: Perseus.

Carey, W. B. (2002). Is ADHD a valid disorder? In P. Jensen \& J. Cooper (Eds.), Attention deficit hyperactivity disorder: State of science, best practices. Kingston NJ: Civic Research Institute.

Cohen, D., Leo, J. L., Stanton, T., Smith, D., McCreedy, K., Laing, M. S., et al. (2002). A boy who stops taking stimulants for "ADHD": Commentaries on a Pediatrics case study. Ethical Human Sciences and Services, 4, 189-209.

DeGrandpre, R. (1999). Ritalin nation. New York: Norton.

Diller, L. H. (1998). Running on Ritalin. New York: Bantam.

Ford, J. D., Racusin, R., Daviss, W. B., Ellis, C. G., Thomas, J., Rogers, K., et al. (1999). Trauma exposure among children with oppositional defiant disorder and attention deficithyperactivity disorder. Journal of Consulting and Clinical Psychology, 67, 786-789.

Ford, J. D., Racusin, R., Ellis, C. G., Daviss, W. B., Reiser, J., Fleischer, A., et al. (2000). Child maltreatment, other trauma exposure, and posttraumatic symptomatology among children with oppositional defiant and attention deficit hyperactivity disorders. Child Maltreatment, 5, 205-217.

Green, M., Wong, M., Atkins, D., Taylor, J., \& Feinleib, M. (1999). Diagnosis of attention deficit hyperactivity disorder. Rockville, MA: Agency for Healthcare Policy and Research.

Hendrick, H. (1997). Constructions and reconstructions of British childhood: An interpretive survey, 1800 to the present. In A. James \& A. Prout (Eds.), Constructing and reconstructing childhood: Contemporary issues in the sociological study of childhood (pp. 28-56). London: Falmer.

Hynd, G. W., \& Hooper, S.R. (1995). Neurological basis of childhood psychopathology. London: Sage.

Joseph, J. (2000). Not in their genes: A critical review of the genetics of attention-deficit hyperactivity disorder. Developmental Review, 20, 539-567.

Joughin, C., \& Zwi, M. (1999). Focus on the use of stimulants in children with attention deficit hyperactivity disorder. Primary evidence-base friefing No.1. London: Royal College of Psychiatrists Research Unit.

Jureidini, J., \& Mansfield, P. (2001). Does drug promotion adversely influence doctors' abilities to make the best decisions for patients? Australasian Psychiatry, 9, 95-100.

Kopelman, L. (1990). On the evaluative nature of competency and capacity judgements. International Journal of Law and Psychiatry, 13, 309-329.

LeFever, G. B., Dawson, K. V., \& Morrow, A. D. (1999). The extent of drug therapy for attention deficit hyperactivity disorder among children in public schools. American Journal of Public Health, 89, 1359-1364.

Leo, J. L., \& Cohen, D. A. (2003). Broken brains or flawed studies? A critical review of ADHD neuroimaging research. The Journal of Mind and Behavior, 24, 29-56.

Mann, E. M., Ikeda, Y., Mueller, C. W., Takahashi, A., Tao, K. T. Humris, E., et al. (1992). Cross-cultural differences in rating hyperactive-disruptive behaviors in children. American Journal of Psychiatry, 149, 1539-1542.

Moll, G., Hause, S., Ruther, E., Rothenberger, A., \& Huether, G. (2001). Early methylphenidate administration to young rats causes a persistent reduction in the density of striatal dopamine transporters. Journal of Child and Adolescent Psychopharmacology, 11, 15-24.

National Institutes of Health. (1998). Diagnosis and treatment of attention deficit hyperactivity disorder. Rockville, MD: Programs and abstracts, NIH Consensus Development Conference.

Olfson, M., Marcus, S. C., Weissman, M. M., \& Jensen, P. S. (2002). National trends in the use of psychotropic medications by children. Journal of the American Academy of Child and Adolescent Psychiatry, 41, 514-521.

Prout, A., \& James, A. (1997). A new paradigm for the sociology of childhood? Provenance, promise and problems. In A. James \& A. Prout (Eds.), Constructing and re-constructing childhood: Contemporary issues in the sociological study of childhood (pp. 1-27). London: Falmer.

Postman, N. (1983). The disappearance of childhood. London: W.H. Allen.

Rapoprt, J. L., Buchsbaum, M. S., Zahn, T. P., Weingartner, H., Lublow, C., \& Mikkelsen, E. J. (1978). Dextroamphetamine: Cognitive and behavioral effects in normal prepubertal boys. Science, 199, 198-214.

Rappley, M. D., Gardiner, J. C., Jetton, J. R., \& Howang, R. T. (1995). The use of methylphenidate in Michigan. Archives of Pediatric and Adolescent Medicine, 149, 675-679.

Schachter, H., Pham, B., King, J., Langford, S., \& Moher, D. (2001). How efficacious and safe is short-acting methylphenidate for the treatment of attention-deficit disorder in children and adolescents? A meta-analysis. Canadian Medical Association Journal, 165, 1475-1488. 
Sonuga-Barke, E. J. S., Minocha, K., Taylor, E. A., \& Sandberg S. (1993). Inter-ethnic bias in teacher's ratings of childhood hyperactivity. British Journal of Developmental Psychology, $11,187-200$.

Sproson, E. J., Chantrey, J., Hollis, C., Marsden, C. A., \& Fonel, K. C. (2001). Effect of repeated methylphenidate administration on presynaptic dopamine and behavior in young adult rats. Journal of Psychopharmacology, 15, 6775.

Stephens, S. (1995). Children and the politics of culture in late capitalism. In S. Stephens (Ed.), Children and the politics of culture. New Jersey: Princeton University Press.
Taylor, E., \& Hemsley, R. (1995). Treating hyperkinetic disorders in childhood. BMJ, 310, 1617-1618.

Timimi, S. (2002). Pathological child psychiatry and the medicalization of childhood. Hove, UK: Brunner-Routledge.

Van Praag, H. M. (1996). Comorbidity (psycho) analysed. British Journal of Psychiatry, 168(Suppl. 30), 129-134.

Zito, J. M., Safer, D. J., DosReis, S., Gardner, J. F., Boles, M., \& Lynch, F. (2000). Trends in prescribing of psychotropic medications to preschoolers. JAMA, 283, 10251030.

Zwi, M., Ramchandani, P., \& Joughlin, C. (2000). Evidence and belief in ADHD. BMJ, 321, 975-976. 